\title{
Development of an Amperometric Glucose Biosensor Based on the Immobilization of Glucose Oxidase on the Se-MCM-41 Mesoporous Composite
}

\author{
Sabriye Yusan, ${ }^{1,2}$ Mokhlesur M. Rahman $\left(\mathbb{D},{ }^{3}\right.$ Nasir Mohamad, ${ }^{3}$ Tengku M. Arrif, ${ }^{3}$ \\ Ahmad Zubaidi A. Latif, ${ }^{4}$ Mohd Aznan M. A., ${ }^{5}$ and Wan Sani B. Wan Nik $\left(\mathbb{1}^{6}\right.$ \\ ${ }^{1}$ Department of Chemistry, Faculty of Science, Universiti Teknologi Malaysia, 81310 Johor Bahru, Johor, Malaysia \\ ${ }^{2}$ Institute of Nuclear Science, Ege University, Bornova, 35100 Izmir, Turkey \\ ${ }^{3}$ Institute for Community Development \& Quality of Life (i-CODE), Universiti Sultan Zainal Abidin, 21300 Kuala Nerus, \\ Terengganu, Malaysia \\ ${ }^{4}$ Faculty of Medicine, Universiti Sultan Zainal Abidin, 21300 Kuala Nerus, Terengganu, Malaysia \\ ${ }^{5}$ Faculty of Medicine, International Islamic University Malaysia, 25200 Kuantan, Malaysia \\ ${ }^{6}$ School of Ocean Engineering, Universiti Malaysia Terengganu, 21300 Kuala Nerus, Terengganu, Malaysia
}

Correspondence should be addressed to Mokhlesur M. Rahman; mokrahman@unisza.edu.my

Received 6 November 2017; Accepted 21 February 2018; Published 10 May 2018

Academic Editor: Larisa Lvova

Copyright (C) 2018 Sabriye Yusan et al. This is an open access article distributed under the Creative Commons Attribution License, which permits unrestricted use, distribution, and reproduction in any medium, provided the original work is properly cited.

A new bioenzymatic glucose biosensor for selective and sensitive detection of glucose was developed by the immobilization of glucose oxidase (GOD) onto selenium nanoparticle-mesoporous silica composite (MCM-41) matrix and then prepared as a carbon paste electrode (CPE). Cyclic voltammetry was employed to probe the catalytic behavior of the biosensor. A linear calibration plot is obtained over a wide concentration range of glucose from $1 \times 10^{-5}$ to $2 \times 10^{-3} \mathrm{M}$. Under optimal conditions, the biosensor exhibits high sensitivity $\left(0.34 \mu \mathrm{A} \cdot \mathrm{mM}^{-1}\right)$, low detection limit $\left(1 \times 10^{-4} \mathrm{M}\right)$, high affinity to glucose $\left(\mathrm{K}_{\mathrm{m}}=0.02 \mathrm{mM}\right)$, and also good reproducibility (R.S.D. $2.8 \%, n=10$ ) and a stability of about ten days when stored dry at $+4^{\circ} \mathrm{C}$. Besides, the effects of $\mathrm{pH}$ value, scan rate, mediator effects on the glucose current, and electroactive interference of the biosensor were also discussed. As a result, the biosensor exhibited an excellent electrocatalytic response to glucose as well as unique stability and reproducibility.

\section{Introduction}

The determination of the glucose level is significant in chemical samples, biological and clinical, as well as in food processing and fermentation [1]. Diabetes mellitus especially is one of the principal causes of demise and disability in the world and is highly responsible for kidney failure, heart disease, and sightlessness. About 200 million people in the world are afflicted with diabetes mellitus [2]. So the determination of blood glucose levels rapidly, conveniently, precisely, and economically is vital for its diagnosis and effective management [3]. Therefore, the development and fabrication of a cost-effective, simple, accurate, portable, and rapid sensor for glucose are socially crucial for diabetes mellitus [4]. For this aim, electrochemical biosensors have been applied successfully for the determination of glucose.

Glucose oxidase (GOD) has been significantly used to check blood glucose levels in diabetes patients mainly due to it being inexpensive, stable, and of practical use [5] and its catalytic ability to glucose. It has a flavin adenine dinucleotide (FAD) redox point, which is entirely surrounded in the apoenzyme. It acts upon by catalysis transfer of the electron from glucose to gluconolactone. The space among its two $\mathrm{FAD} / \mathrm{FADH}_{2}$ midpoints and surface the electrode is so long that explicit transfer of the electron from the enzyme to the electrode is tricky to be realized [6]. Most glucose 
TABLE 1: Comparison between current market CGMS/sensor results devices [26-28].

\begin{tabular}{|c|c|c|c|c|}
\hline Brand & Guardian Real-Time & MiniMed 530G with Enlite & $\begin{array}{l}\text { Dexcon G4 } \\
\text { Platinum }\end{array}$ & FreeStyle \\
\hline Company & Medtronic & Medtronic & Dexcom & Abbott \\
\hline FDA approved date & 2006 & 2007 & 2007 & 2008 \\
\hline Sensor life (d) & 3 & 6 & 7 & 5 \\
\hline Sensor style & Insertion under skin & Insertion under skin & $\begin{array}{l}\text { Insertion } \\
\text { under skin }\end{array}$ & Insertion under skin \\
\hline $\begin{array}{l}\text { Startup initialization } \\
\text { time }(\mathrm{h})\end{array}$ & 2 & 2 & 2 & 10 \\
\hline $\begin{array}{l}\text { Calibration }(\mathrm{Y} / \mathrm{N}) \text { with } \\
\text { finger-stick test }\end{array}$ & $\begin{array}{l}\mathrm{Y}, 2 \mathrm{~h} \text { after insertion, the first } \\
6 \mathrm{~h} \text {, and then every } 12 \mathrm{~h}\end{array}$ & $\begin{array}{l}\mathrm{Y}, 2 \mathrm{~h} \text { after insertion, the first } \\
6 \mathrm{~h} \text {, and then every } 12 \mathrm{~h}\end{array}$ & $\mathrm{Y}$, every $12 \mathrm{~h}$ & $\begin{array}{l}\mathrm{Y} \text {, approximately } 1,2,10,24, \\
\text { and } 72 \mathrm{~h} \text { after insertion }\end{array}$ \\
\hline
\end{tabular}

CGMS = continuous glucose monitor system; FDA = Food and Drug Administration.

measurements are based on the immobilization of glucose oxidase (GOD) for detecting $\mathrm{H}_{2} \mathrm{O}_{2}$ concentration which is obtained from the GOD enzymatic reaction $[7,8]$ as illustrated by the following steps:

$$
\begin{aligned}
\text { GOX }_{\mathrm{FAD}}+\text { glucose } & \rightarrow{ }^{\text {GOX }} \mathrm{FADH}_{2}+\text { gluconolactone (enzymatic) } \\
\mathrm{GOX}_{\mathrm{FADH}} & \rightarrow{ }^{\mathrm{GOX}} \mathrm{FAD}+2 e+2 \mathrm{H}^{+} \text {(electrochemical) } \\
\mathrm{GOX}_{\mathrm{FADH}}+\mathrm{O}_{2} & \rightarrow{ }^{\mathrm{GOX}} \mathrm{FAD}+\mathrm{H}_{2} \mathrm{O}_{2} \text { (enzymatic) } \\
\mathrm{GOX}_{\mathrm{FAD}}+2 e+2 \mathrm{H}^{+} & \rightarrow{ }^{\mathrm{GOX}} \mathrm{FADH}_{2} \text { (electrochemical) }
\end{aligned}
$$

There are many methods for the GOD immobilization such as covalent cross-linking [9-11], electrochemical polymerization [12], sol-gel encapsulating [13], and adsorption methods [14]. Among these immobilization methods, adsorption is the simplest. Adsorption can retain the bioactivities of the immobilized enzyme well because their action needs no chemical reagents. Biosensors based on the adsorption of protein, however, are limited by the amount of the immobilized enzyme on the electrode surface and are therefore unstable. The sensitivity of the biosensor is directly proportional to the enzyme surface density on the electrode; hence, an increase in enzyme loading on the biosensor surface may result in a significant improvement in its sensitivity [15]. But it is well known that the direct electron communication between the protein and the electrode transducer is difficult because the redox sites of the protein are deeply seated in the protein shell. In order to improve the direct electrochemistry of the redox protein, nanomaterials, such as carbon nanotubes $[4,5,16,17]$, metal nanoparticles (gold, iron, nickel, etc.) [2, 18-20], $\mathrm{ZnO}$ nanotubes [21], platinum or sputtered platinum [22, 23], glassy carbon [24], and CdS nanoparticles [25], have been used widely due to their catalytic ability and good biocompatibility properties. A comparison of the current market glucose sensor results with published articles is given in Table 1 [26-28]. Nanoparticles can offer many advantages, such as large surface-to-volume ratio, high surface reaction activity, and strong adsorption ability to immobilize the desired biomolecules. Many metal and semiconductor nanoparticles have been chosen to prepare modified electrodes [29]. Nanomaterials, which were used as a carrier in enzyme sensor, not only increase the stability and the amount of the immobilized enzyme but also improve the catalytic activity of the protein and the responsibility of the sensor [18].
Also newly, a sequence of inorganic porous materials such as mud [30], montmorillonite [31], and mesoporous silicate $[6,32-34]$ has been proven to be certifying as the immobilization patterns because of their high chemical, mechanical, and thermal solidity as well as good adsorption due to its large specific surface area and absorbency. So the combination of mesoporous molecular sieves into redox enzymes could deliver a bioactive compound [6].

In this paper, we describe a simple route to the production of the Se-MCM-41 mesoporous electrode. The preparation method is simple, and selenium nanoparticles may be readily formed on a carbon paste electrode surface constructing a simple, economical, and accurate amperometric sensor for glucose. The electrode current response of glucose shows excellent stability and reproducibility. The prepared sensors can be used for the determination of glucose in human blood.

\section{Experimental}

2.1. Materials. Glucose oxidase (GOD from Aspergillus niger, E. C. 1.1.3.4), glutaraldehyde (50 wt. \%), and glucose were purchased from Sigma. Ferrocene (98\%, Merck) was used as received. All other reagents were of analytical grade and used without further purification. Stock solutions of glucose were prepared in $0.05 \mathrm{M}$ phosphate buffer $(\mathrm{pH} 7.0)$ and mutarotated for at least $24 \mathrm{~h}$ before use. All solutions were prepared and made up with doubledistilled water (DDW). Carbon graphite powder (Ultra F, 200 meshes, Johnson Matthey) and paraffin oil (from Fluka) has been used for the preparation of carbon paste electrode (CPE). 
2.2. Preparation of Se-MCM-41/GOD Particles. The composite material was added in the flask containing $25 \mathrm{~mL}$ glutaraldehyde solution ( $5 \%$ in $0.05 \mathrm{M}$ phosphate buffer, $\mathrm{pH}$ 6.62). The container containing the mixture of reactants was stirred at room temperature for three hours. The solution was then filtered and washed several times with deionized water to remove excess glutaraldehyde. Tollens' reagent was used to test the presence of glutaraldehyde. For this purpose, Tollens' reagent (the silver mirror test) test was carried out until a colorless solution is produced, thus indicating the absence of excess glutaraldehyde.

The glutaraldehyde cross-linked Se-MCM-41 mesopore composite has mixed with $3 \mathrm{~mL}$ of $2 \mathrm{mg} \cdot \mathrm{mL}^{-1} \mathrm{GOD}$ solution in a phosphate buffer. The reaction mixture was incubated at $0-5^{\circ} \mathrm{C}$ with shaking $(100 \mathrm{rpm})$ for six hours. The supernatant was removed, and the composite was washed three times with phosphate buffer solution ( $\mathrm{pH} 6,0.05 \mathrm{M}$ ). The GOD immobilized material was recovered from the solution and stored at $+4^{\circ} \mathrm{C}$ for subsequent uses.

2.3. GOD Activity Assay. Activity assay of the enzyme was carried out using $o$-dianisidine dye. The colorless dye in the reduced form reacts in the presence of peroxidase (POD) and oxidizing agent to give a brown colored solution, measurable at $500 \mathrm{~nm}$ using UV-Vis [35]. The GOD catalyzes the oxidation of glucose to $\delta$-gluconolactone, producing $\mathrm{H}_{2} \mathrm{O}_{2}$ which

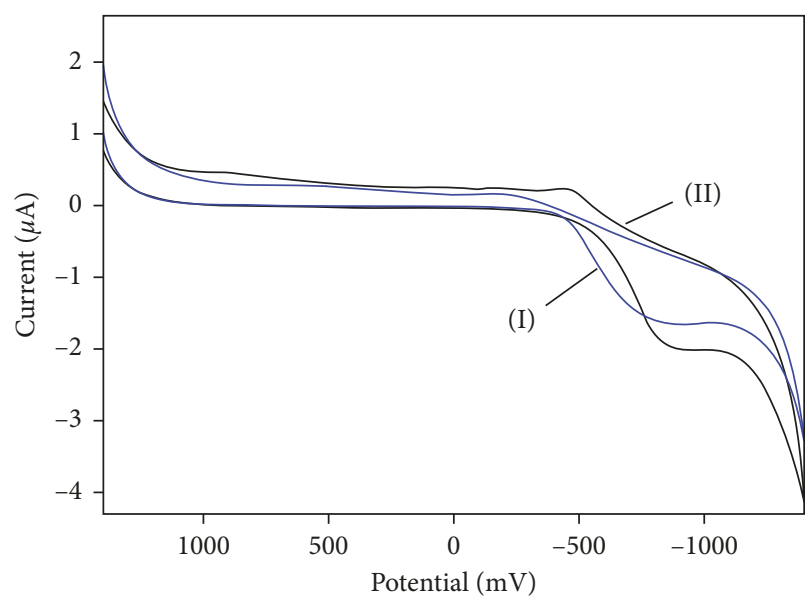

Figure 1: Cyclic voltammogram of (I) Se-MCM-41 and (II) immobilized GOD to the Se-MCM-41 in $0.05 \mathrm{M}$ phosphate buffer $(\mathrm{pH} 7)$ at a scan rate of $20 \mathrm{mV} \cdot \mathrm{s}^{-1}$.

is then measured indirectly by the oxidation of the dye in the presence of POD, following the reaction as shown in (2) and (3). The specific activity of glucose oxidase was calculated according to (2), and it was found that the $0.116 \mathrm{U} / \mathrm{mg}$ solid produced is higher than the one reported previously [11]:

$$
\begin{aligned}
\beta \text {-D-glucose }+\mathrm{O}_{2}+\mathrm{H}_{2} \mathrm{O} \stackrel{\mathrm{GOD}}{\longrightarrow} \delta \text {-glucono-1,5-lactone }+\mathrm{H}_{2} \mathrm{O}_{2} \\
\mathrm{H}_{2} \mathrm{O}_{2}+o \text {-dianisidine (reduced) } \stackrel{\text { POD }}{\longrightarrow} o \text {-dianisidine (oxidized) } \\
\beta \text {-D-glucose }+\mathrm{O}_{2}+\mathrm{H}_{2} \mathrm{O} \stackrel{\text { GOD }}{\longrightarrow} \delta \text {-glucono-1,5-lactone }+\mathrm{H}_{2} \mathrm{O}_{2}
\end{aligned}
$$

The amount of enzyme is calculated using the following formula: enzyme (units $/ \mathrm{ml})=\left(\Delta A_{500 \mathrm{~nm}} / \mathrm{min}\right.$ test $-\Delta A_{500 \mathrm{~nm}} / \mathrm{min}$ blank) $(3.1) \cdot(\mathrm{df}) /(7.5) \cdot(0.1)$, where $3.1=$ volume (in milliliters) of assay; $\mathrm{df}=$ dilution factor; $7.5=$ millimolar extinction coefficient of oxidized $o$-dianisidine at $500 \mathrm{~nm} ; 0.1=$ volume (in milliliters) of enzyme used.

\subsection{Electrode Preparation and Electrochemical Instrumen-} tation. The electrochemical behavior of the Se-MCM-41GOx mesopore composite sample was studied using a working electrode made of carbon paste (CPE) modified with the solid particles. This electrode was prepared by mixing $5 \mathrm{mg}$ of the obtained composite with $50 \mathrm{mg}$ of graphite $(1: 10)$. After adding a few drops of paraffin oil, the mixture was homogenized using a pestle in an agate mortar. Then, the combination was housed in a polyethylene tube (inner diameter $2.4 \mathrm{~mm}$ ) and polished on a smooth paper layer before conducting each of the experiments. An electric contact was made by a copper wire through the back of the electrode.

Electrochemical experiments were carried out in a conventional three-electrode cell comprising the modified carbon paste as the working electrode, an $\mathrm{Ag} / \mathrm{AgCl} / \mathrm{KCl}$ $3 \mathrm{M}$ ) reference electrode, and a platinum wire as the auxiliary electrode. Experiments of all electrochemical were done with 757 VA Computrace (Metrohm) using a potential scan of $-1400 \mathrm{mV}$ to $+1400 \mathrm{mV}$ to fit the window.

All experiments performed at room temperature in $0.05 \mathrm{M}$ (pH 7.0) phosphate buffer as the supporting electrolyte. Electrolyte solutions were deoxygenated with nitrogen bubbling for at least $5 \mathrm{~min}$ and a nitrogen atmosphere kept over the solution during electrochemical measurements.

\section{Results and Discussion}

3.1. Cyclic Voltammograms of GOx to the Se-MCM-41 Composite. To verify the electrochemical properties of the Se-MCM-41/GOD/CPE, we carried out the direct electrochemical measurement of the immobilized GOD on the SeMCM-41/CPE using typical CPE electrodes without GOD. Figure 1 displays the typical cyclic voltammograms (CV) for Se-MCM-41/CPE (I) and Se-MCM-41/GOD/CPE (II) in $0.05 \mathrm{M}$ deoxygenated phosphate buffer solution ( $\mathrm{pH} 7.0$ ) over the potential range from 1.4 to $-1.4 \mathrm{~V}$ at $20 \mathrm{mV} \cdot \mathrm{s}^{-1}$ scan 


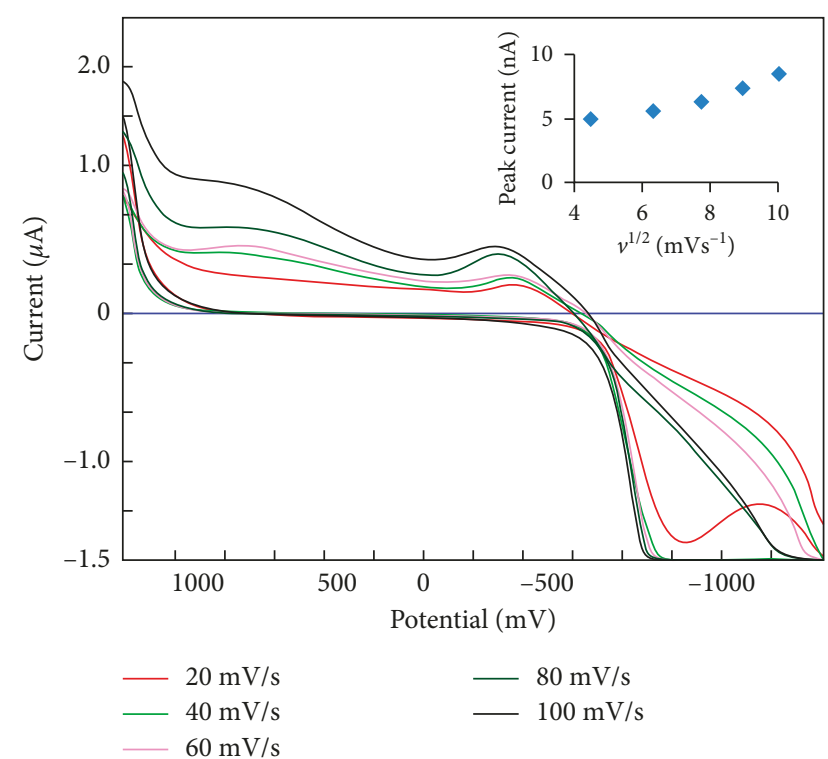

FIgUre 2: Cyclic voltammograms of Se-MCM-41/GOD/CPE in $\mathrm{pH}$ $7.0 \mathrm{PBS}$ at $20,40,60,80$, and $100 \mathrm{mV} \cdot \mathrm{s}^{-1} \mathrm{scan}$ rates (from inner to outer). Inset: peak currents of plots versus $v^{1 / 2}$.

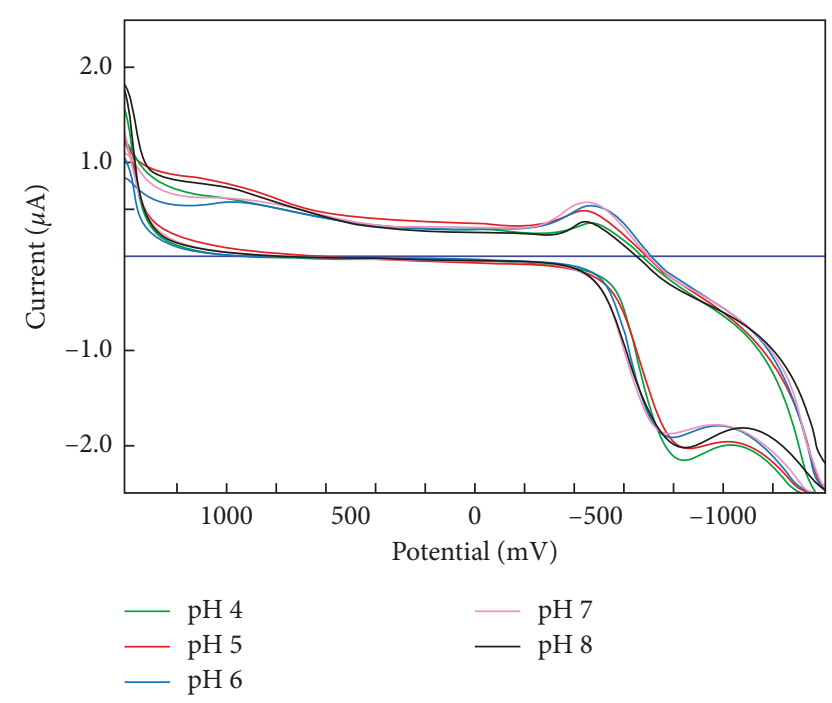

FIgURE 3: Effect of $\mathrm{pH}$ on the response of the biosensor (Se-MCM$41 / \mathrm{GOD} / \mathrm{CPE}$ ) in the presence of $2 \mathrm{mM}$ glucose.

rate. As seen from the plot (I), no redox peaks were observed using the typical CPE electrode which indicated Se-MCM-41 as being electroinactive in the potential window. Plot II shows the CV of GOD immobilized on Se-MCM-41/CPE, and a pair of oxidation-reduction peak appears. The results indicated that the reaction of catalytic oxidation of glucose by GOD occurred and the immobilized GOD retained its electrocatalytic activity for the oxidation of glucose $[36,37]$.

Flavin adenine dinucleotide is a part of the GOD molecule and is known to undergo a redox reaction, where two electrons and two protons were exchanged, and the electrochemical response of GOD immobilized on the solid surface is due to the redox reaction of FAD [38]. The FAD redox potentials in various enzymes ranged from 190 to $-490 \mathrm{mV}$. In plot (II), the FAD peak appeared about $-470 \mathrm{mV}$, which was acceptable, and suggested that GOD bound to the Se-MCM-41 composite was active in the electron transfer [11].

The main cause for the transfer electron between the silicabased electrode and the enzyme might be due to the electrostatic relations, such as hydrogen bonding and hydrophilic attraction between MCM-41 and glucose oxides (GOD). The communication between MCM-41 and GOD is much stronger than that between CPE and GOD due to the presence of Si-OH groups on the external surface of MCM-41. In our study, the glucose oxides (GOD) should be immobilized on the external surface of Se-MCM-41 by physical adsorption because the pore diameter of GOD (about 4-6 nm) is bigger than the size of Se-MCM-41 (about $2.7 \mathrm{~nm}$ ) [6]. Due to the presence of many acidic silicon hydroxyl (Si-OH) groups on the outer surface of the Se-MCM-41, the oxidation reaction of GOD will be not easy thermodynamically.

3.2. Effect of Scan Rate. The effect of scan rate on the electrochemistry of the immobilized GOD is shown in Figure 2. With increasing scan rate, the anodic peak currents of the GOD increased linearly, and the anodic peak potential of GOD is shifted to a more positive value. The dependence of the current $\left(I_{\mathrm{p}}\right)$ on the square root of the scan rate $\left(v^{1 / 2}\right)$ (inset in Figure 2) is an essential diagnostic criterion for establishing the type of reaction mechanism by cyclic voltammetry. It suggests that the Se-MCM-41 composite is sufficiently thick and the electron transfer between selenium MCM-41 composite is slow, leading to the system to mimic semi-infinite linear diffusion [39].

3.3. Effect of pH on the Peak Current. The effect of $\mathrm{pH}$ on the anodic peak current was investigated over the range $\mathrm{pH}$ 4.0-8.0 (buffer solution of $\mathrm{K}_{2} \mathrm{HPO}_{4}-\mathrm{KH}_{2} \mathrm{PO}_{4}$ ) in the presence of $2 \mathrm{mM}$ glucose at $25^{\circ} \mathrm{C}$. The resulting $I$ versus $\mathrm{pH}$ (4-8) data are illustrated in Figure 3. As can be seen, the peak potential of GOD is dependent on the solution $\mathrm{pH}$ with the maximum response observed at $\mathrm{pH}$ 7.0, which is consistent with that of most GOD-based glucose biosensors. Therefore, we fixed the solution $\mathrm{pH}$ at 7.0 for the investigation of the analytical performance of Se-MCM-41 carbon paste electrode covered with GOD. Either the strongly acidic solution or alkaline solution would decrease the bioactivity of the enzyme. Thus, the proposed biosensor was practical to detect glucose levels in real samples at neutral $\mathrm{pH}$ value [40]. These results are similar to previously reported values of optimum $\mathrm{pH}$ for the use of glucose oxidase with other artificial electron acceptors [5, 29, 41-43].

3.4. Effect of the Glucose Concentration. The cyclic voltammograms of Se-MCM-41/GOD/CPE with successive addition of glucose to air-saturated $0.05 \mathrm{M}$ PBS ( $\mathrm{pH} 7.0$ ) are shown in Figure 4. The peak current of Se-MCM-41/GOD/CPE increased linearly with increasing concentration of glucose up to $2 \mathrm{mM}$. The calibration range of glucose concentration was prepared from 0.01 to $12.0 \mathrm{mM}$. The linear response range of the sensor 


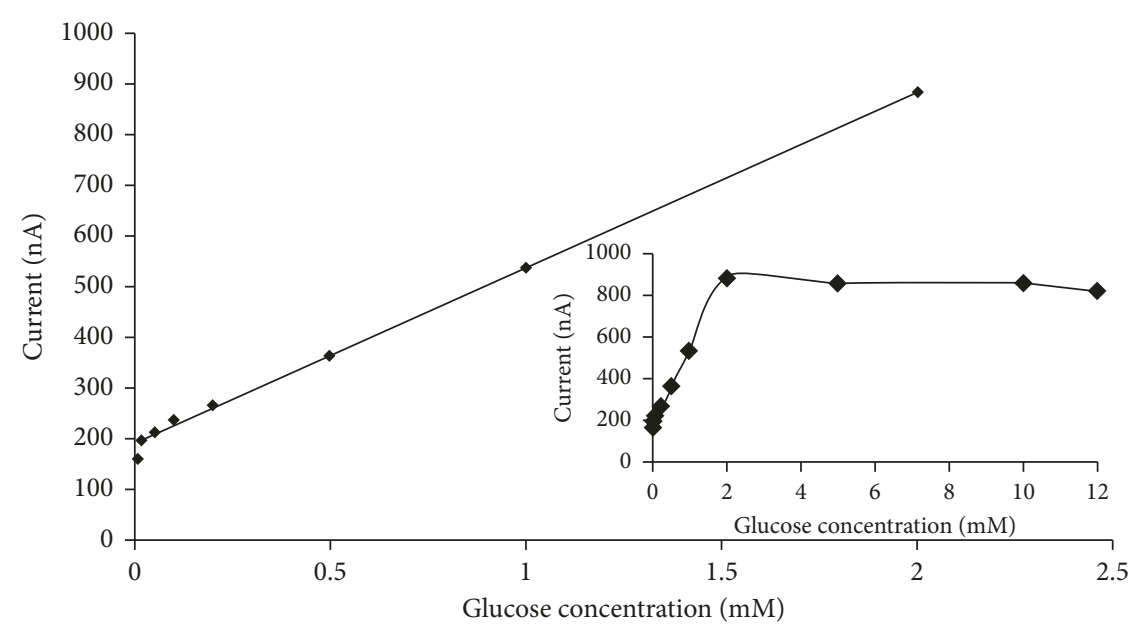

FIgURE 4: Correlation between the maximum current and the concentration of glucose.

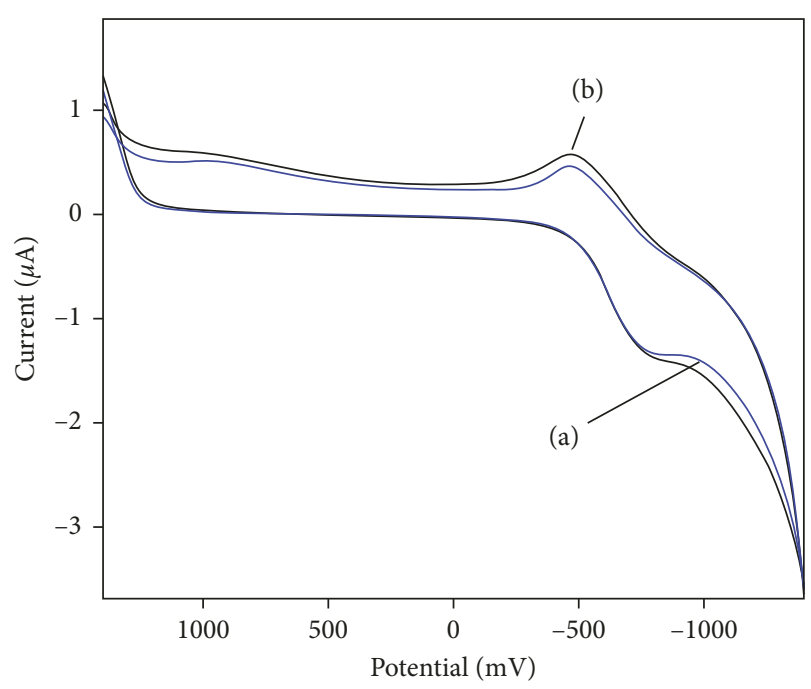

Figure 5: Cyclic voltammograms of Se-MCM-41/GOD/CPE in $0.05 \mathrm{M}$ PBS ( $\mathrm{pH} 7.0$ ) containing $0.2 \mathrm{mM}$ ferrocene in the absence (a) and presence (b) of $2.0 \mathrm{mM}$ glucose.

to glucose concentration was from 0.01 to $2.0 \mathrm{mM}$ with a correlation coefficient of 0.997 . The sensitivity of Se-MCM$41 / \mathrm{GOD} / \mathrm{CPE}$ to glucose was found to be $0.34 \mu \mathrm{A} \cdot \mathrm{mM}^{-1}$, which is higher than values found in the literature for $\mathrm{GOx} / \mathrm{PtNP} / \mathrm{CNTs} /$ carbon paste $\left(0.28 \mu \mathrm{A} \cdot \mathrm{mM}^{-1}\right)$, Nafion/GOx film electrode $\left(51.0 \mathrm{nA} \cdot \mathrm{mM}^{-1}\right)$, and poly $(o$-phenylenediamine $)$ covered screen-printed electrode $\left(16.6 \mathrm{nA} \cdot \mathrm{mM}^{-1}\right)$ [44-47].

According to the Lineweaver-Burk form of the Michaelis-Menten equation, the relation between the reciprocal of the response current and the reciprocal of glucose concentration can be obtained. The apparent MichaelisMenten constant $\left(K_{m}\right)$, an indicator of enzyme-substrate reaction kinetics, can be used to evaluate the biological activity of the immobilized enzyme, and this constant can be calculated from the Lineweaver-Burk equation, given below:

$$
\frac{1}{I_{\mathrm{ss}}}=\left(\frac{K_{m}}{I_{\max }}\right)\left(\frac{1}{C_{g}}\right)+\frac{1}{I_{\max }},
$$

where $C_{g}$ is the substrate concentration, $I_{\text {ss }}$ is the steadystate current, and $I_{\max }$ is the maximum current measured under substrate saturation [48].

Here, Michaelis-Menten constant $K_{m}$ and the maximum response current of the biosensor based on the Se-MCM41/GOD electrode are calculated and equal to $0.02 \mathrm{mM}$ and $0.45 \mu \mathrm{A}$, respectively. The low $K_{m}$ value of $0.02 \mathrm{mM}$ indicates the affinity of the enzyme to the electrode, which was smaller than those of $5.20,22.8,14.4,21$, and $37.6 \mathrm{mM}$, for immobilized GOD [5, 45-48], indicating that the GOD immobilized on Se-MCM-41/GOD has high affinity to glucose. These results imply that the biosensor based on the Se-MCM-41/GOD electrode is valuable and sensitive.

3.5. Glucose Bioelectrocatalytic Oxidation. Although the direct transfer electron of GOD was achieved, some intermediaries are still used to accelerate the electron transfer rate between electrode and GOD $[8,9]$. To increase the response current, ferrocene, a satisfactory electron transfer mediator has been used in the biosensor based on Se-MCM-41/GOD/CPE [44]. Figure 5 has shown cyclic voltammograms of the SeMCM-41/GOD/CPE in $\mathrm{N}_{2}$-saturated, $\mathrm{pH}$ 7.0 PBS containing $0.2 \mathrm{mM}$ ferrocene as the facilitator. When $2.0 \mathrm{mM}$ glucose was added to the solution, the anodic peak current increased, using ferrocene as the mediator in $\mathrm{N}_{2}$-saturated solutions, consequently, demonstrating that Se-MCM-41/GOD/CPE is able to electrocatalyze the oxidation of glucose. These results can be explained from the following equations:

$$
\begin{aligned}
& \text { Glucose }+ \text { GOD }(\text { ox }) \rightarrow \text { gluconolactone }+ \text { GOD }(\text { red }) \\
& \text { GOD }(\text { red })+2 \text { ferrocene } \rightarrow \text { GOD }(\text { ox })+2 \text { ferrocene }+2 \mathrm{H}^{+} \\
& 2 \text { ferrocene } \rightarrow 2 \text { ferrocene }+2 e^{-}
\end{aligned}
$$

3.6. Analytical Performance. The amperometric response characteristics of the enzyme electrode are affected by the electroactive interferents. In this section, the effects of these 
factors on the behavior of the GOD electrode, reproducibility, and stability have been investigated in detail and discussed accordingly.

3.6.1. Reproducibility. The reproducibility of the glucose biosensor was investigated by successively detecting $0.10 \mathrm{mM}$ glucose ten times; the relative standard deviation (RSD) calculated was $2.8 \%$. The RSD for the detection of $1.0 \mathrm{mM}$ glucose with three sensors prepared independently under the same conditions was $3.6 \%$, demonstrating a good reproducibility of the measurements performed.

3.6.2. Stability. The stability of the enzyme electrode was also investigated by amperometric measurements. It retained $91 \%$ of its initial current response, when the enzyme electrode was stored at $+4^{\circ} \mathrm{C}$ for glucose after intermittent use over a 10 days interval. So, it can be presumed that the presence of nanoparticle selenium incorporated MCM-41 is very efficient in retaining the enzyme activity of GOD.

3.6.3. Interferences. The effects of interference have been observed by testing the amperometric response of $0.1 \mathrm{mM}$ glucose in the presence of their normal physiological concentration $(0.1 \mathrm{mM}$ for ascorbic acid and $0.1 \mathrm{mM}$ for citric acid) [48]. When the glucose-to-interferent concentration ratio was $1: 1$, a decrease of $14 \%$ for ascorbic acid or an increase of $25 \%$ for citric acid in the current value of the $0.5 \mathrm{mM}$ glucose was observed, respectively. In addition, when the ratio of glucose to interferent was $1: 2$ for the ascorbic acid or citric acid, the response current decreased significantly as compared to the response for the $1: 1$ ratio. These results suggested that the presence of interferences such as ascorbic or citric acid did not affect the current measurement of the GOD significantly using the Se-MCM41/GOD. The results also suggested that the proposed glucose has high selectivity and compatibility on the SeMCM-41/GOD as the support material for the sensor.

\section{Conclusion}

The preparation of a new type of glucose oxidase electrode using nanoselenium particles and the MCM-41 mesoporous composite was well demonstrated. The preparation of the electrode is easy, fast, and reproducible. Cyclic voltammetric results confirmed that the prepared electrode presents a highly electrocatalytic activity for the oxidation of glucose. The optimum $\mathrm{pH}$ was obtained at $\mathrm{pH} 7.0$ which is the optimal environment herein. Since the $\mathrm{pH}$ value of human blood was around 7.4, the potentiometric glucose biosensor was suitable for measuring the concentration of glucose in human blood. Under the optimized experimental conditions, the catalytic currents are linear to the concentrations of glucose from $1 \times 10^{-5}$ to $2 \times 10^{-3} \mathrm{M}$. The detection limit was $1 \times 10^{-4} \mathrm{M}$ with a signal to noise ratio of 3 . The sensor exhibits good reproducibility and stability during the measurement. At the same time, the biosensor demonstrates high sensitivity $\left(0.34 \mu \mathrm{A} \cdot \mathrm{mM}^{-1}\right)$. Besides, the biosensor possesses high sensitivity and excellent chemical and mechanical stability. All the results show that the prepared Se-MCM-41/GOD can provide a promising material for biosensor designs and other biological applications.

\section{Conflicts of Interest}

The authors declare that they have no conflicts of interest.

\section{Authors' Contributions}

Sabriye Yusan performed the experiments, analysed the data, and prepared the manuscript. (Late) Alias Mohd Yusof and Mokhlesur M. Rahman designed, supervised, analysed the data, and edited the manuscript. Tengku M. Ariff, Nasir Mohamad, Ahmad Zubaidi A. Latif, Mohd Aznan Md Aris, and Wan Sani B. Wan Nik provided financial support and performed critical analysis.

\section{Acknowledgments}

The authors are profoundly grateful for the financial support given by the Faculty of Science, Universiti Teknologi Malaysia (UTM), Research Management Center of International Islamic University Malaysia, and Universiti Sultan Zainal Abidin through the Project no. EDW B 14-217-1102 and NRGS/PR057-1, respectively.

\section{References}

[1] S. Liu and H. Ju, "Reagentless glucose biosensor based on direct electron transfer of glucose oxidase immobilized on colloidal gold modified carbon paste electrode," Biosensors and Bioelectronics, vol. 19, no. 3, pp. 177-183, 2003.

[2] M. Rahman, A. J. S. Ahammad, J.-H. Jin, S. J. Ahn, and J.-J. Lee, "A comprehensive review of glucose biosensors based on nanostructured metal-oxides," Sensors, vol. 10, no. 5, pp. 4855-4886, 2010.

[3] A. E. G. Cass, G. Davis, G. D. Francis et al., "Ferrocene-mediated enzyme electrode for amperometric determination of glucose," Analytical Chemistry, vol. 56, no. 4, pp. 667-671, 1984.

[4] M. M. Rahman, A. Umar, and K. Sawada, "Development of amperometric glucose biosensor based on glucose oxidase coimmobilized with multi-walled carbon nanotubes at low potential," Sensors and Actuators B: Chemical, vol. 137, no. 1, pp. 327-333, 2009.

[5] X. Kang, Z. Mai, X. Zou, P. Cai, and J. Mo, "A novel glucose biosensor based on immobilization of glucose oxidase in chitosan on a glassy carbon electrode modified with goldplatinum alloy nanoparticles/multiwall carbon nanotubes," Analytical Biochemistry, vol. 369, no. 1, pp. 71-79, 2007.

[6] Z. H. Dai, J. Ni, X. H. Huang, G. F. Lu, and J. C. Bao, "Direct electrochemistry of glucose oxidase immobilized on a hexagonal mesoporous silica-MCM-41 matrix," Bioelectrochemistry, vol. 70, no. 2, pp. 250-256, 2007.

[7] J. Li and X. Lin, "Glucose biosensor based on immobilization of glucose oxidase in poly(o-aminophenol) film on polypyrrole- $\mathrm{Pt}$ nanocomposite modified glassy carbon electrode," Biosensors and Bioelectronics, vol. 22, no. 12, pp. 2898-2905, 2007.

[8] A. Vaze, N. Hussain, C. Tang, D. Leech, and J. Rusling, "Biocatalytic anode for glucose oxidation utilizing carbon nanotubes for direct electron transfer with glucose oxidase," 
Electrochemistry Communications, vol. 11, no. 10, pp. 20042007, 2009.

[9] Z. Lin, J. Chen, and G. Chen, "An ECL biosensor for glucose based on carbon-nanotube/nafion film modified glass carbon electrode," Electrochimica Acta, vol. 53, no. 5, pp. 2396-2401, 2008.

[10] C.-W. Liao, J.-C. Chou, T.-P. Sun, S.-K. Hsiung, and J.-H. Hsieh, "Preliminary investigations on a glucose biosensor based on the potentiometric principle," Sensors and Actuators B: Chemical, vol. 123, no. 2, pp. 720-726, 2007.

[11] S. Akella and C. K. Mitra, "Electrochemical studies of glucose oxidase immobilized on glutathione coated gold nanoparticles," Indian Journal of Biochemistry \& Biophysics, vol. 44, pp. 82-87, 2007.

[12] M.-Q. Liu, J.-H. Jiang, Y.-L. Feng, G.-L. Shen, and R.-Q. Yu, "Glucose biosensor based on immobilization of glucose oxidase in electrochemically polymerized polytyramine film and overoxidised polypyrrole film on platinized carbon paste electrode," Chinese Journal of Analytical Chemistry, vol. 35, no. 10, pp. 1435-1438, 2007.

[13] G. Changa, Y. Tatsu, T. Goto, H. Imaishi, and K. Morigaki, "Glucose concentration determination based on silica sol-gel encapsulated glucose oxidase optical biosensor arrays," Talanta, vol. 83, no. 1, pp. 61-65, 2010.

[14] H. Dai, X. Wu, H. Xu, Y. Wang, Y. Chi, and G. Chen, "A highly performing electrochemiluminescent biosensor for glucose based on a polyelectrolyte-chitosan modified electrode," Electrochimica Acta, vol. 54, no. 19, pp. 4582-4586, 2009.

[15] Q. Gao, Y. Guo, W. Zhang, H. Qi, and C. Zhang, "An amperometric glucose biosensor based on layer-by-layer GOx-SWCNT conjugate/redox polymer multilayer on a screen-printed carbon electrode," Sensors and Actuators B: Chemical, vol. 153, no. 1, pp. 219-225, 2010.

[16] C. Deng, J. Chen, X. Chen, C. Xiao, L. Nie, and S. Yao, “Direct electrochemistry of glucose oxidase and biosensing for glucose based on boron-doped carbon nanotubes modified electrode," Biosensors and Bioelectronics, vol. 23, no. 8, pp. 1272-1277, 2008.

[17] J. Zhang, M. Feng, and H. Tachikawa, "Layer-by-layer fabrication and direct electrochemistry of glucose oxidase on single wall carbon nanotubes," Biosensors and Bioelectronics, vol. 22, no. 12, pp. 3036-3041, 2007.

[18] X. Zhi-Gang, L. Jian-Ping, T. Li, and C. Zhi-Qiang, “A novel electrochemiluminescence biosensor based on glucose oxidase immobilized on magnetic nanoparticles," Chinese Journal of Analytical Chemistry, vol. 38, no. 6, pp. 800-804, 2010.

[19] X. Wang, Y. Zhanga, C. E. Banks, Q. Chen, and X. Ji, "Nonenzymatic amperometric glucose biosensor based on nickel hexacyanoferrate nanoparticle film modified electrodes," Colloids and Surfaces B: Biointerfaces, vol. 78, no. 2, pp. 363-366, 2010.

[20] F. N. Comba, M. D. Rubianes, P. Herrasti, and G. A. Rivas, "Glucose biosensing at carbon paste electrodes containing iron nanoparticles," Sensors and Actuators B: Chemical, vol. 149, no. 1, pp. 306-309, 2010.

[21] T. Kong, Y. Chen, Y. Ye, K. Zhang, Z. Wang, and X. Wang, "An amperometric glucose biosensor based on the immobilization of glucose oxidase on the $\mathrm{ZnO}$ nanotubes," Sensors and Actuators B: Chemical, vol. 138, no. 1, pp. 344-350, 2009.

[22] S. Y. Lu, C. E. Li, D. D. Zhang et al., "Electron transfer on an electrode of glucose oxidase immobilized in polyaniline," Journal of Electroanalytical Chemistry, vol. 364, no. 1-2, pp. 31-36, 1994.
[23] R. J. H. J. Os van, A. Bult, C. G. J. Koopal, and W. P. Bennekom van, "Glucose detection at bare and sputtered platinum electrodes coated with polypyrrole and glucose oxidase," Analytica Chimica Acta, vol. 335, no. 3, pp. 209-216, 1996.

[24] X. Xu, J. Chen, W. Li, Z. Nie, and S. Yao, "Surface nanocrystallization of glassy carbon electrode: application in direct electrochemistry of glucose oxidase," Electrochemistry Communications, vol. 10, no. 10, pp. 1459-1462, 2008.

[25] Y. Huang, W. Zhang, H. Xiao, and G. Li, “An electrochemical investigation of glucose oxidase at a CdS nanoparticles modified electrode," Biosensors and Bioelectronics, vol. 21, no. 5, pp. 817-821, 2005.

[26] G. McGarraugh, "The chemistry of commercial continuous glucose monitors," Diabetes Technology \& Therapeutics, vol. 11, no. 1, pp. 17-24, 2009.

[27] T. D. Mall, "Comparison of current continuous glucose monitors (CGMs)," 2014, http://www.diabetesnet.com/diabetestechnology/meters-monitors/continuous-monitors/comparecurrent-monitors.

[28] S. Colberg, 50 Secrets of the Longest Living People with Diabetes, Da Capo Press, Boston, MA, USA, 1st edition, 2008.

[29] B. Zheng, S. Xie, L. Qian, H. Yuan, D. Xia, and M. M. F. Choi, "Gold nanoparticles-coated eggshell membrane with immobilized glucose oxidase for fabrication of glucose biosensor," Sensors and Actuators B: Chemical, vol. 152, no. 1, pp. 49-55, 2010.

[30] C. Lei, F. Lisdat, U. Wollenberger, and F.W. Scheller, "Cytochrome c/clay modified electrode," Electroanalysis, vol. 11, no. 4, pp. 274-276, 1999.

[31] C. Fan, Y. Zhuang, G. Li, J. Zhu, and D. Zhu, "Direct electrochemistry and enhanced activity for hemoglobin in a sodium montmorillonite film," Electroanalysis, vol. 12, no. 14, pp. 1156-1157, 2000.

[32] Z. Dai, S. Liu, H. Ju, and H. Chen, "Direct electron transfer and enzymatic activity of hemoglobin in a hexagonal mesoporous silica matrix," Biosensors and Bioelectronics, vol. 19, no. 8, pp. 861-867, 2004.

[33] L. Zhang, Q. Zhang, and J. Li, "Direct electrochemistry and electrocatalysis of hemoglobin immobilized in bimodal mesoporous silica and chitosan inorganic-organic hybrid film," Electrochemistry Communications, vol. 9, no. 7, pp. 1530-1535, 2007.

[34] J. D. Webb, S. MacQuarrie, K. McEleney, and C. M Crudden, "Mesoporous silica-supported Pt catalysts: an investigation into structure, activity, leaching and heterogeneity," Journal of Catalysis, vol. 252, no. 1, pp. 97-109, 2007.

[35] H. U. Bergmeyer, K. Gawehnand, and M. Grassl, "Methods of Enzymatic Analysis,” H. U. Bergmeyer, Ed., vol. 1, pp. 457-458, Academic Press Inc., New York, NY, USA, 2nd edition, 1974.

[36] L. Xu, Y. Zhu, Y. Li, X. Yang, and C. Li, "Bienzymatic glucose biosensor based on co-immobilization of glucose oxidase and horsedish peroxidase on gold nanoparticles-mesoporous silica matrix," in Proceedings of 2nd International Nanoelectrics Conference IEEE, pp. 390-393, Shanghai, China, 2008.

[37] J. Wang, Analytical Electrochemistry, John Wiley \& Sons, Inc., Hoboken, NJ, USA, 3rd edition, 2006.

[38] X. Kang, J. Wang, H. Wu, I. A. Aksay, J. Liu, and Y. Lin, "Glucose oxidase-graphene-chitosan modified electrode for direct electrochemistry and glucose sensing," Biosensors and Bioelectronics, vol. 25, no. 4, pp. 901-905, 2009.

[39] A. Mugweru, B. L. Clark, and M. V. Pishko, "Electrochemical sensor array for glucose monitoring fabricated by rapid immobilization of active glucose oxidase within photochemically 
polymerized hydrogels," Journal of Diabetes Science and Technology, vol. 1, no. 3, pp. 366-371, 2007.

[40] Y. Liu, S. Wu, H. Ju, and L. Xu, "Amperometric glucose biosensing of gold nanoparticles and carbon nanotube multilayer membranes," Electroanalysis, vol. 19, no. 9, pp. 986-992, 2007.

[41] Z. Wen, D. Lju, B. Ye, and X. Zhou, "Development of disposable electrochemical sensor with replaceable glucose oxidase tip," Analytical Communications, vol. 34, no. 1, pp. 27-30, 1997.

[42] R. Antiochia and L. Gorton, "Development of a carbon nanotube paste electrode osmium polymer-mediated biosensor for determination of glucose in alcoholic beverages," Biosensors and Bioelectronics, vol. 22, no. 11, pp. 2611-2617, 2007.

[43] W. Liang and Y. Zhuobin, "Direct electrochemistry of glucose oxidase at a gold electrode modified with single-wall carbon nanotubes," Sensors, vol. 3, no. 12, pp. 544-554, 2003.

[44] M. Yang, Y. Yang, Y. Liu, G. Shen, and R. Yu, "Platinum nanoparticles doped sol-gel/carbon nanotubes composite electrochemical sensors and biosensors," Biosensors and Bioelectronics, vol. 21, no. 7, pp. 1125-1131, 2006.

[45] K. Balasubramanian and M. Burhard, "Biosensors based on carbon nanotubes," Analytical and Bioanalytical Chemistry, vol. 385, no. 3, pp. 452-468, 2006.

[46] M. E. Ghica and C. M. A. Brett, "Development of a carbon film electrode ferrocene-mediated glucose biosensor," Analytical Letters, vol. 38, no. 6, pp. 907-920, 2005.

[47] M. Yuqing, C. Jianrong, and W. Xiaohua, "Construction of a Glucose biosensor by immobilizing glucose oxidase within a poly(ophenylenediamine) covered screen-printed electrode," Online Journal of Biological Sciences, vol. 6, no. 1, pp. 18-22, 2006.

[48] D. Pan, J. Chen, S. Yao, L. Nie, J. Xia, and W. Tao, "Amperometric glucose biosensor based on immobilization of glucose oxidase in electropolymerized o-aminophenol film at copper-modified gold electrode," Sensors and Actuators B: Chemical, vol. 104, no. 1, pp. 68-74, 2005. 

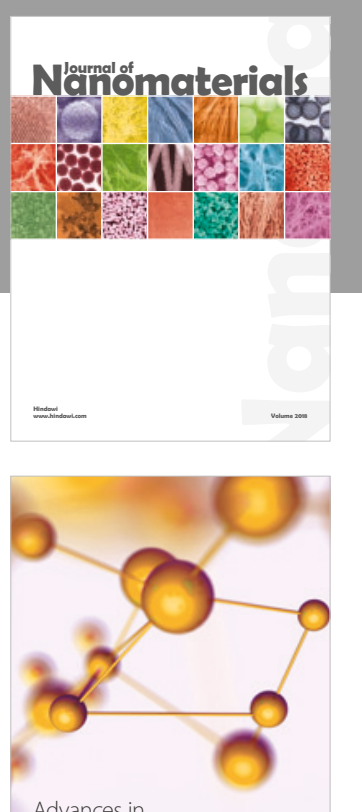

Physical Chemistry
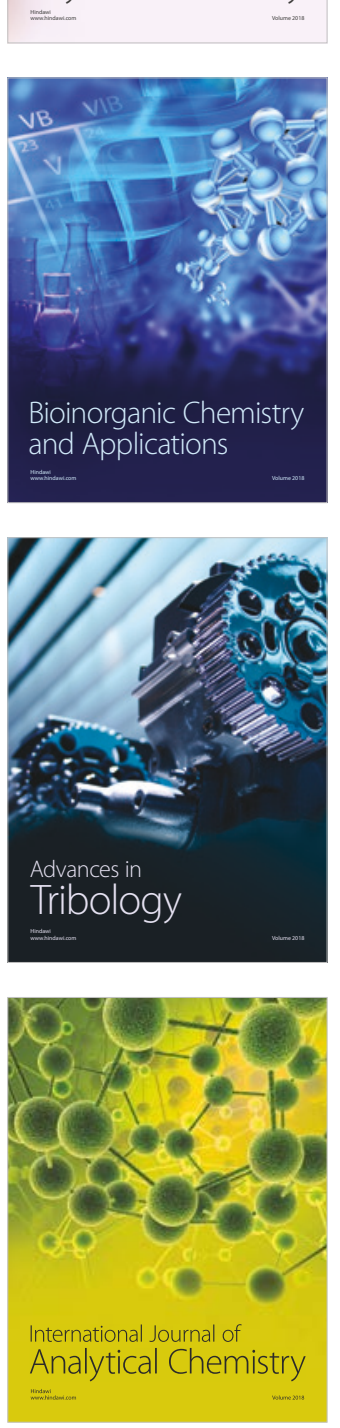

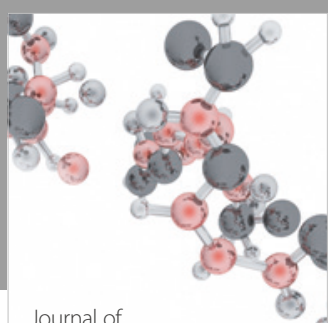

Analytical Methods

in Chemistry

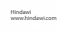

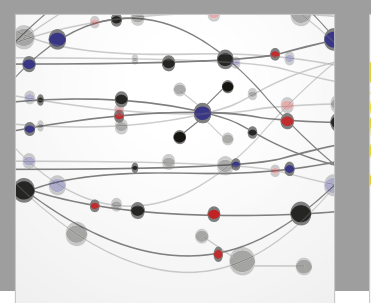

The Scientific World Journal

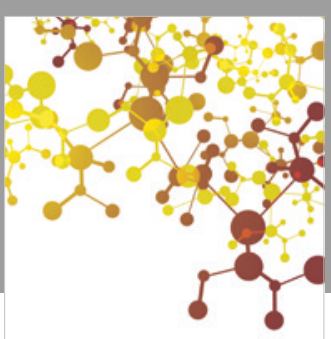

Journal of

Applied Chemistry
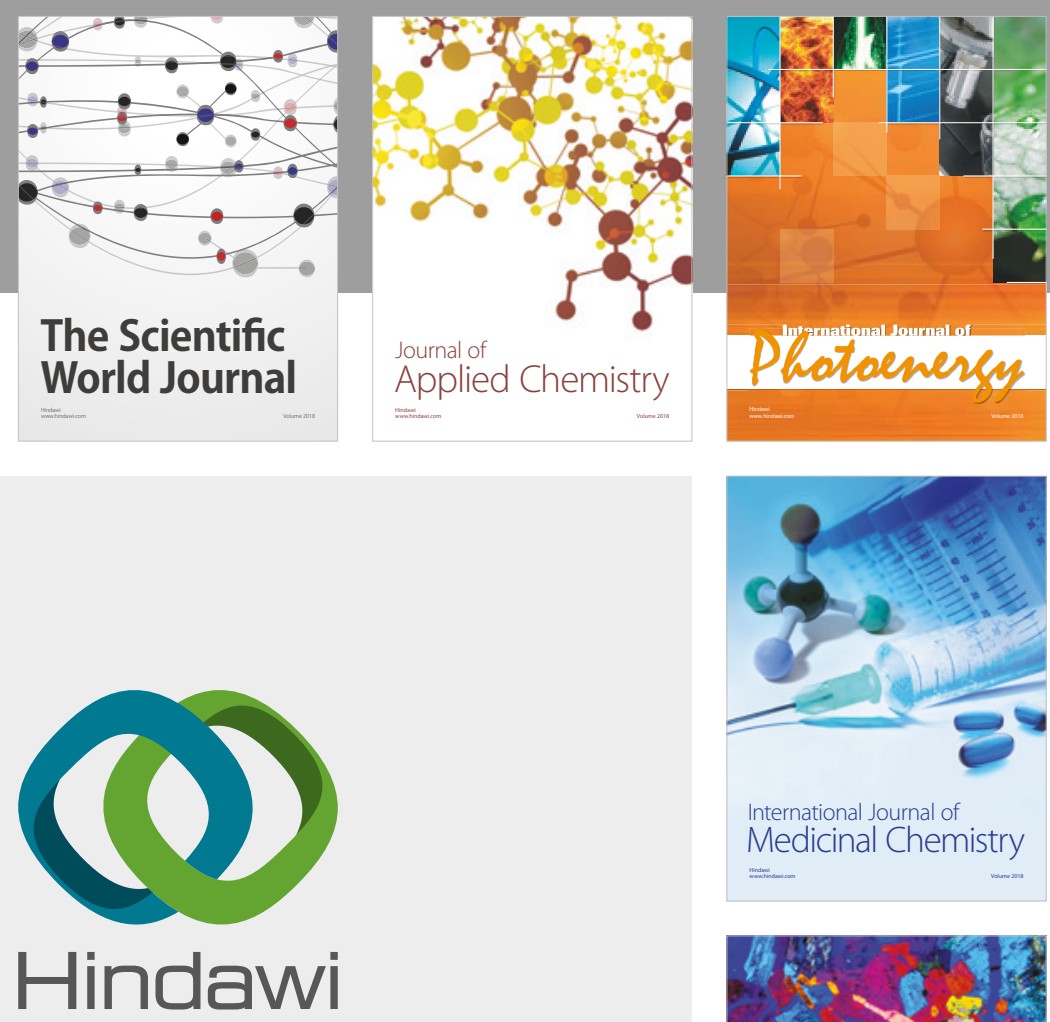

Submit your manuscripts at

www.hindawi.com
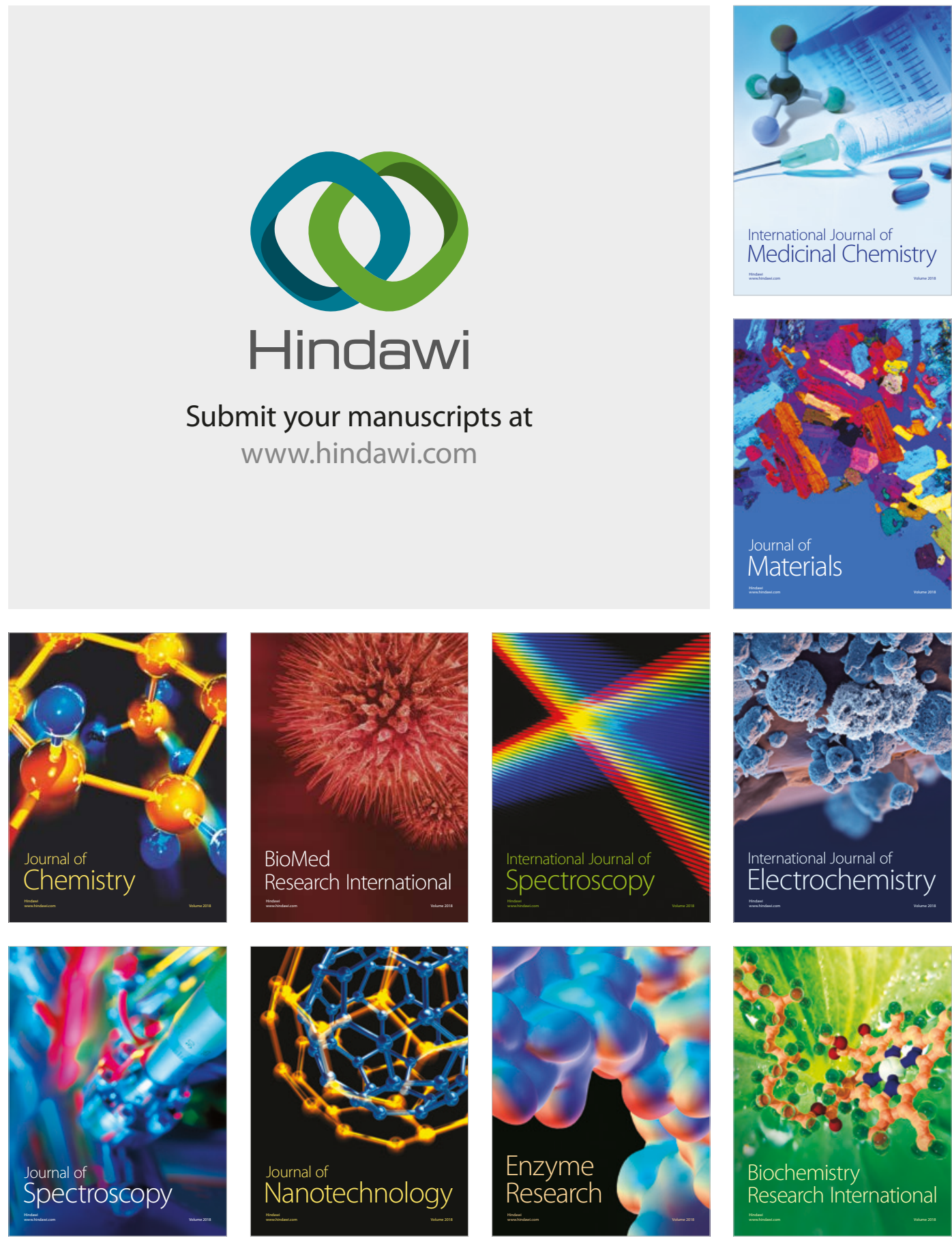
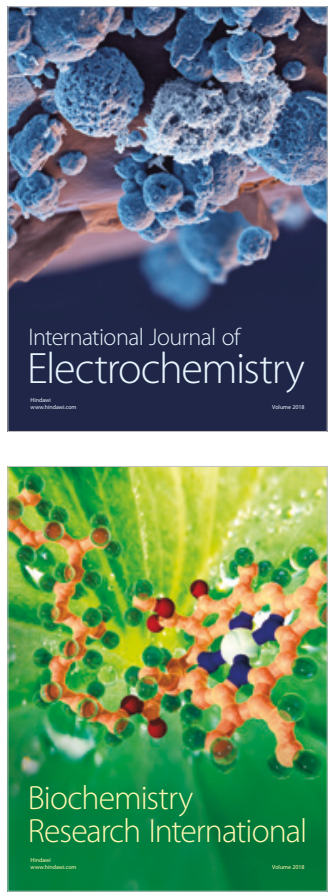